\title{
Interpretation on coexistence or association of thrombocytopenia with malaria
}

\author{
Niraj Nepal ${ }^{1}$, Prabesh Kumar Choudhary ${ }^{1}$, Nirajan Mainali ${ }^{1}$

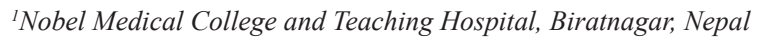

\section{Keywords: \\ Fever; \\ Malaria; \\ Thrombocytopenia;}

\begin{abstract}
Background: Malaria is a major health problem especially in developing countries. It is a major cause of morbidity and mortality especially in the tropics. There are several hematological changes in this particular disease, which includes thrombocytopenia, anemia, atypical lymphocytosis and infrequently intravascular coagulation. The aim of the study is to detect and compare the severity of various hematological changes, especially thrombocytopenia in the particular type of malaria.
\end{abstract}

Materials and Methods: This was an observational study done on the patients attending the outpatient and inpatient departments clinically suspected for malaria in Nobel Medical College, Biratnagar, Nepal. Thick and thin slides were made and stained with Leishman's stain for malarial parasites and also antigen tests were included wherever necessary. Other tests included were, complete blood counts.

Results: Amongst the included 800 patients with suspicion of malaria, 135 (17\%) patients demonstrated malarial parasites on peripheral blood film. Male predominance in male to female predominance of 3.5:1 was observed. Total number of 120 out of 135 had thrombocytopenia. Thrombocytopenia was observed higher in P. Vivax (79.3\%) followed by Mixed infection (17\%) and P. falciparum (3.7\%) respectively.

Conclusion: Anemia with mainly thrombocytopenia was mainly seen in P. Vivax type followed by P. Falciparum. Since thrombocytopenia is associated with malaria, which is demonstrated in our study, treating physicians should keep malaria as one of the differential diagnosis in patients with fever and low platelets.

\section{Correspondence:}

Dr. Niraj Nepal

Nobel Medical College and Teaching Hospital, Biratnagar, Nepal.

ORCID ID: 0000-0001-5863-5445

Email:nepalniraj@gmail.com

Received : February 24 2019 ; Accepted : March 14 $4^{\text {th }} 2019$; Published : March $29^{\text {th }} 2019$

Citation: Nepal N, Choudhary PK, Mainali N. Interpretation on co-existence or association of thrombocytopenia with malaria. J Pathol Nep 2019;9:1453-6. DOI: 10.3126/jpn.v9i1.23442

Copyright: This is an open-access article distributed under the terms of the Creative Commons Attribution 4.0 International License, which permits unrestricted use, distribution, and reproduction in any medium, provided the original author and source are credited.

\section{INTRODUCTION}

Malaria is a major health problem especially in developing countries, such as Asia and Africa. It is a major cause of morbidity and mortality especially in the tropics. Inspite of advancement in technology it still continues to be a major health problem in most of the populated countries, which poses an economic burden to the concerned countries ${ }^{1}$ It is stated that more than $40 \%$ of the world population reside in malaria-endemic area and it is predictable that 300-500 million cases and 1.5-2.7 million deaths occurs each year. ${ }^{2}$ The mortality rate is increased by $20 \%$ in severe types of malaria (parasitemia $>5 \%)^{3}$. Since hematological system is the main targets of malaria, several complications are 
seen in association with malaria and these complications play significant role in giving rise to serious complications. The abnormalities include anemia, thrombocytopenia, atypical lymphocytosis and in lesser degree disseminated intravascular coagulation ${ }^{4}$. Other findings observed are leucopenia, leukocytosis, eosinophilia and monocytosis ${ }^{3}$. Thrombocytopenia comprises of $70 \%$, severe anemia $25 \%$ in patients suffering with malaria, blood cell count can be normal or low, leukocytosis i.e. high blood cell count comprises of less than $5 \%$ which is considered to be a bad prognostic factor. ${ }^{5}$ Amongst the observed hematological complications, thrombocytopenia is most common and is seen in both Plasmodium (P.). Vivax and P. Falciparum types. When thrombocytopenia observed in peripheral blood film which lacks the normal quantity in patients presenting with fever, it is a clue indicating that the patient is suffering from malaria. ${ }^{4}$ Since the exact mechanism of thrombocytopenia is not clear, it is assumed that immune mediated lysis, sequestration in the spleen, dyspoetic process in bone marrow with decreased platelet production play a major role in the process. ${ }^{5}$ The aim of the study was to detect and compare the severity of various hematological changes, especially thrombocytopenia in the particular type of malaria.

\section{MATERIALS AND METHODS}

This observational cross-sectional study was conducted in Nobel Medical College, Biratnagar, Nepal from August 2017 to December 2018. Permission was obtained from the Institutional Review Committee. Clinically suspected cases of malaria in patients presenting with fever were included in the study. Patients with features of bleeding disorders, chronic liver disease, thrombocytopenia and drug intake or conditions were excluded. Blood parameters were calculated using automated Accurex CBC-330 Hematology Analyzer machine.

Thick and thin blood films were made using two slides, stained using Leishman's stain and malarial parasites were identified and confirmed for the diagnosis of malaria. Malarial positive slides were peer reviewed by a panel of pathologists for further confirmation, identification of the specific species type. All stages of hemoparasite were appreciated in the slides examined, including schizonts, trophozoites and ring forms. Ring forms and trophozoites were mainly appreciated in P. vivax species and gametocyte forms in P. falciparum species. Final reevaluation for platelet counts was done. Data were included in the Microsoft Excel and descriptive analysis was performed.

\section{RESULTS}

Amongst the included 800 patients with suspicion of malaria, $135(17 \%)$ patients demonstrated malarial parasites on peripheral blood film. A male predominance was observed being male to female ratio $3.5: 1$ the total number of males included was $105(78 \%)$ and females
Table 1: Distribution according to age group $(n=135)$

\begin{tabular}{|lc|}
\hline Age Group (years) & Number of Patients (\%) \\
\hline $\mathbf{0 - 1 0}$ & $3(2.2 \%)$ \\
\hline $\mathbf{1 1 - 2 0}$ & $22(16.2 \%)$ \\
\hline $\mathbf{2 1 - 3 0}$ & $53(39.2 \%)$ \\
\hline $\mathbf{3 1 - 4 0}$ & $34(25.1 \%)$ \\
\hline $\mathbf{4 1 - 5 0}$ & $15(11.1 \%)$ \\
\hline $\mathbf{5 1 - 6 0}$ & $4(2.9 \%)$ \\
\hline $\mathbf{6 1 - 7 0}$ & $4(2.9 \%)$ \\
\hline
\end{tabular}

Table 2: Malaria species distribution $(n=135)$

\begin{tabular}{lcc}
\hline $\begin{array}{l}\text { Malaria Plasmodium } \\
\text { Species }\end{array}$ & Frequency & Percentage (\%) \\
\hline Plasmodium Vivax & 107 & $79.3 \%$ \\
Plasmodium Falciparum & 5 & $3.7 \%$ \\
$\begin{array}{l}\text { Mixed Plasmodium } \\
\text { Infection }\end{array}$ & 23 & $17 \%$
\end{tabular}

were $30(22 \%)$. The age group included was divided into 7 categories and the mean age being 19.3 years which ranged from 1 to 70 years. Maximum recorded cases were between the age group 21 to 30 years of age and the minimum of age group was 0 to 10 years of age. (Table 1)

Out of the total 135 patients, $79.3 \%$ (107) were infected with Plasmodiaum (P.) Vivax and 23 patients (17\%) had mixed infection with both P. Vivax and P. Falciparum. (Table 2)

Amongst the total number of cases, 120 (88.9\%) had thrombocytopenia. Thrombocytopenia was observed in both the forms of malarial species. (Table 3) Patients with P. vivax infection and mixed infection caused significant drop in platelet counts in grade III; comprising of $42.05 \%$ of cases of $\mathrm{P}$. vivax and $30.43 \%$ cases in mixed infection while $40 \%$ of cases of P. falciparum in grade IV. Of 800 cases for suspicion of malaria presenting with fever, 135 cases demonstrated malarial infection on smear and 120 of the patients presented with thrombocytopenia. The sensitivity and specificity of this was $88.9 \%$ and $85.2 \%$ respectively.

\section{DISCUSSION}

Malaria seems to be of a great heath burden in most places of the world mainly caused by P. Vivax and P. Falciparum, which seems to be endemic in many african countries, asian countries as well as in Nepal too. Malaria causing several hematological abnormalities, such as thrombocytopenia and anemia can be the hallmark leading to the clue to the diagnosis. ${ }^{6}$ The out numberings of patients in the present study were between the ages of 21 to 30 years of age in contrast to the other studies which reported mean age of 38.7 Information regarding the gender and age is scarce but some studies have reported a high burden in males compared to females ${ }^{1}$ and similar result has been shown in the present study. Dhungat et $a l^{8}$ showed male to female 
Table 3: Grading of thromobcytopenia and prevalence of Plasmodium spp. (n=120)

\begin{tabular}{lcccc}
\hline \multirow{2}{*}{ Platelet (cumm) } & $\begin{array}{c}\text { Grade } \\
\text { (Thrombocytopenia) }\end{array}$ & P Vivax & P. Falciparum & Mixed infection \\
\cline { 3 - 5 } & Grade I & 13 & 1 & 2 \\
$\mathbf{7 5 , 0 0 0}-\mathbf{1 5 0 , 0 0 0}$ & Grade II & 24 & 1 & 3 \\
$\mathbf{2 5 , 0 0 0}-\mathbf{5 0 , 0 0 0}$ & Grade III & 45 & 1 & 7 \\
$<\mathbf{2 5 , 0 0 0}$ & Grade IV & 18 & 2 & 3
\end{tabular}

ratio of $68 \%$ and $32 \%$ which is almost in close concordance to the present study (M-78\% and F-22\%). Outdoor activity and less protection from mosquito bite is one of the key factors for higher risk in males.

It has been reported that $\mathrm{P}$. vivax is the major malaria parasite in subcontinents for the disease process. ${ }^{9}$ Several studied have shown P. vivax as the dominant species but the percent positivity is varied $\left(56.5 \% \%^{8} ; 69 \%{ }^{9}\right.$ and $\left.51.6 \%{ }^{9-11}\right)$. Similar result was obtained in the present study, comprising of $79.3 \%$ followed by a small number $3.7 \%$ of $P$. falciparum and $17 \%$ for mixed infection. However, a higher incidence of P. falciparum was reported in north eastern states of India. ${ }^{13}$

As observed in our study, thrombocytopenia is a common feature of acute malaria and can occur in both P. vivax and P. faclciparum infections regardless of the severity. ${ }^{4}$ The inconsistent degree of reduction of circulating platelet count is reported consistently in different species of malaria. ${ }^{14}$ Reduction in the normal quantity of platelet count on a blood film accompanied by fever which is a diagnostic clue in presence of malarial infection. ${ }^{14}$ It is used as an indicator of malaria in patients presenting with fever of unknown origin. ${ }^{15}$ Patients suffering from malaria when develop thrombocytopenia seldom bleed, whatever the grade of decrease in platelets count ${ }^{16}$, but in contrary no casualties of bleeding were reported in the present study.

Association of thrombocytopenia with malaria has been done by several observational studies and has also been confirmed but the exact cause of thrombocytopenia is still difficult to find. Several causes have been reported as the cause and association of thrombocytopenia with disturbances in coagulation profiles, bone marrow alterations, splenomegaly, oxidative stress and antibody mediated platelet destruction. ${ }^{17-18}$ High tolerance to low platelet count is observed in malaria as observed in our study too. ${ }^{19}$ In spite of very low platelet count up to 20,000 /cumm, no bleeding tendencies and casualties were observed in the patients. In several studied including the present one, thrombocytopenia has not been associated with any morbidity or bleeding complications. ${ }^{19}$ Enhanced aggregation and activation of platelets has been explained to tolerance to low platelet counts in malaria. ${ }^{7}$ Increased hemostatic responses due to hyperactive platelets has been explained to be the reason of less bleeding tendency in acute malarial infections inspite of significant decrease in platelet counts. ${ }^{19}$

Several studied have been conducted regarding the grading

DOI : 10.3126/jpn.v9i1.23442 of thrombocytopenia which was actually based on the levels of decreased platelet count similar to the present study. ${ }^{20-22}$ Khan et al had conducted a study where the maximum number of patients was $21 \%$ in grade I while in contrary, the largest group in the present study were in group III comprising of 42.05 percent. $^{20}$

\section{CONCLUSION}

Anemia with mainly thrombocytopenia was mainly seen in P. Vivax type followed by P. Falciparum. Since thrombocytopenia is associated with malaria, which is demonstrated in our study, treating physicians should keep malaria as one of the differential diagnosis in patients with fever and low platelets.

\section{Conflict of interest: None}

\section{REFERENCES}

1. Jairajpuri Z, Rana S, Jaseem S, Jeetly S. Thrombocytopenia and Malaria: A coincidental co-existence or a significant association? An analysis. Annals of Pathology and laboratory Medicine. 2015;02:4753.

2. World Health Organiztion. World malaria situation in 1994. Parts 1-111. Weekly Epidemiol Rec 1997;72:269-90. Crossref

3. Murphy GS, Oldfield EC. Falciparum malaria. Inf Dis Clin North Am 1996; 10:747-75. Crossref

4. Jadhav UM, Patkar VS, Kadman NN. Thrombocytopenia in Malarial correlation with type and severity of Malaria. JAPI 2004:52;615-8. $\underline{\text { Crossref }}$

5. Latif N, Ejaz SM, Hanif S, Memon H. Clinical and Hematological patterns in patients of Plasmodium Vivax. Medical Channel 2012;18:48-51. Crossref

6. Menom AR, Afsar S. Thrombocytopenia in hospitalized malaria patients. Pak J Med Sci 2006;22:141-3.

7. Bashwari LA, Mandil AM, Bahnassy AA, Al-Shamsi MA, Bukhari HA. Epidemiological profile of malaria in a university hospital in the eastern region of Saudi Arabia. Saudi Med J 2001;2001:113-8.

8. Dhungat MP, Dhungat PP. Thrombocytopenia in patients of Malariacorrelation with type of Malaria and it's Clinical Significance; Online International Interdisciplinary Research Journal, 2013;3:21-6.

9. Lathia TB, Joshi R. Can hematological parameters discriminate malaria from non-malarious acute febrile illness in the tropics? Indian J Med 2004;58:239-44.

10. Yasinzai MI, Kakar Suleman, Khel JK. Incidence of human malaria infection in northern hilly region of Baluchistan adjoining with NWFP Pakistan, district Zohb; PaK J BioSci 2008; 15:1620-4.

11. Gupta NK, Bansal SB, Jain UC, Sahare K. Study of thrombocytopenia in patients of malaria. Tropical Parasitol 2013;3: 8-61. Crossref

12. Shetty GM, Bhandary N. Leukocyte count as a marker of severity in malaria. IJBR 2012;3:88-93. 
13. Faseela TS, Ronald AR, Anita KB, Chaithra SM, Yashwanth R. Diagnostic Value of Platelet Count in Malaria. JCDR 2011;5:464-6.

14. Rabha B, Goswani D, Dhiman S, Das NG, Talukdar PK, Nath MJ, Baruah I, Bhola RK, Singh L. A cross sectional Investigation of Malaria Epidemiology among Seven Tea Estates in Assam, India. J Parasit Dis 2012;36:1-6. Crossref

15. Oh MD, Shin H, Shin D. Clinical features of Vivax malaria. Am J Trop Med Hyg 2001; 65:143-6 $\underline{\text { Crossref }}$

16. Facer CA. Hematological aspect of malaria In: Infection and Hematology. Oxford Butterworth Heinemann Ltd;1994. pp259-94.

17. Essien EM. Medical hypothesis: the circulating platelet in acute malaria infection. Brit J Hematol 1989;72:589-90. Crossref
18. Jamal Khan SS, Khan FR, Usman M, Zahid S. Malaria can lead to thrombocytopenia," Rawal Medical Journal 2008;33:183-5.

19. Rasheed A, Saeed S, Khan A. Platelet count in malaria. Pakistan Journal of Phytopathology, 2008;19:86-8.

20. Khan SJ, Abbas Y, Marwat MA. Thrombocytopenia as an indicator of Malaria in Adult population. Malaria Research and Treatment 2012, www.hindwani.com/journals/mrt/2012 Article ID 405981, 4 pages.

21. Patel U, Gandhi G, Friedman S, Nirajan S, "Thrombocytopenia in Malaria," J Natl Med Assoc 2004;96:1212-4. Crossref

22. Shrikant J, Srinivas S, Krishna CRPS, Ramaulu PR. Prevalence of thrombocytopenia in a diagnosed case of malaria in rural population of South India. J Dr NTR Uni Health Sci 2012;1:52-5. 